\title{
High- versus low-dose proton pump inhibitors post endoscopic hemostasis in hemodialysis cases with peptic ulcer bleeding
}

\author{
A.A. Salman 1 , M.A. Salman², M.D. Sarhan², H El-Din Shaaban², M. Yousef ${ }^{4}$, A. Ibrahim¹, M. Tourky ${ }^{5}$, A. Youssef ${ }^{1}$, \\ M. El Sherbiny ${ }^{1}$
}

(1) Internal Medicine Department, Faculty of medicine, Cairo University, Egypt ; (2) General Surgery Department, Faculty of medicine, Cairo University, Egypt ; (3) National Hepatology and Tropical Medicine Research Institute ; (4) Tropical Medicine Department, Faculty of medicine, Cairo University, Egypt ; (5) General surgery senior registrar, Alawi Tunsi, Saudi Arabia.

\begin{abstract}
Post-endoscopic hemostasis treatment is not adequately addressed in high-risk patients on regular hemodialysis (HD) with emergency peptic ulcer bleeding. This study aimed to compare post-endoscopic high- versus low-dose proton pump inhibitors (PPIs) for peptic ulcer bleeding in patients undergoing regular HD.

This prospective study comprised 200 patients on regular hemodialysis having emergency peptic ulcer bleeding confirmed at endoscopy and managed with endoscopic hemostasis. Half of the patients received high-dose intensive regimen and the other half received the standard regimen. Patients who were suspected to have recurrent bleeding underwent a second endoscopy for bleeding control. The primary outcome measure was rate of recurrent bleeding during period of hospitalization that was detected through second endoscopy.

Rebleeding occurred in 32 patients; 15 in the High-Dose Cohort and 17 in the Low-Dose Control $(p=0.700)$. No significant differences between the two dose cohorts regarding the time of rebleeding $(p=0.243)$, endoscopic hemostasis mode $(p=1.000)$, and need for surgery $(p=0.306)$. The high-dose regimen Inhospital mortality in high-dose group was $9.0 \%$ compared to $8.0 \%$ in the low-dose group $(p=0.800)$. Apart from the pre-hemostatic Forrest classification of ulcers, there were no significant differences between patients with re-bleeding ulcers $(n=32)$ and those with non-rebleeding $(n=168)$. Rebleeding was more common in class Ia, i.e. spurting bleeders $(\mathrm{p}<0.001)$.

Endoscopic hemostasis followed by the standard low-dose PPI regimen of $40 \mathrm{mg}$ daily $\mathrm{IV}$ boluses is safe and effective option for bleeding peptic ulcers in the high-risk patients under regular hemodialysis. (Acta gastroenterol. belg., 2021, 84, 3-8).
\end{abstract}

Keywords : Proton pump inhibitors, endoscopic hemostasis, hemodialysis patients, peptic ulcer bleeding.

\section{Introduction}

Bleeding from upper gastrointestinal (GI) tract is not uncommon clinical emergency that may present with life-threatening hemorrhage (1). The origin of bleeding can be variceal or non-variceal. Variceal bleeding is a detrimental adverse outcome of portal hypertension, that necessitates prompt and efficient management (2). On the other hand, The major contributor to non-variceal upper GI bleeding is peptic ulcer disease (3) ; it accounts roughly for $20-50 \%$ of cases in recent estimates $(4,5)$. Gastrointestinal bleeding is a common complication of end-stage renal disease and is the reason for death in 3-7\% of these cases (6-8). Gastroduodenal ulcers and erosions are common causes of upper GI bleeding in hemodialysis patients $(9,10)$. This group of patients is at increased risk of upper GI bleeding due to several factors including high prevalence of arteriovenous malformations, associated co-morbidities, anemia $(11,12)$, and exposure to clottingmodifying medications, especially when on regular hemodialysis (13).

The optimum management of emergency upper GI bleeding includes prompt resuscitation, risk stratification, pharmacologic and endoscopic intervention, and postprocedure therapy (14). Several previous clinical trials and meta-analyses have confirmed the significance of endoscopic hemostasis in the reduction of mortality, need for surgery, and ulcer rebleeding in high-risk patients (15-17). The beneficial effect of endoscopic hemostasis was confirmed in patients on maintenance hemodialysis with upper GI bleeding (18). However, the ideal postendoscopic hemostasis treatment was not adequately addressed in literature.

Therefore, this study aimed to compare the use of high- and low-dose proton pump inhibitors (PPIs) following endoscopic control of bleeding peptic ulcers in patients undergoing regular hemodialysis regarding inhospital rebleeding rate, need for surgical intervention, transfusion demands, period of hospitalization, and death.

\section{Subjects and methods}

This is a prospective observational non-randomized study that was made to assess the role PPI therapy in decreasing recurrent bleeding of peptic ulcer after endoscopic hemostasis in high-risk cases on regular hemodialysis. The current work was done in the period from May 2013 to December 2017. All eligible patients who presented within the study period were included in this study. The study protocol received approval by the local ethical committee. Written informed consents were given from all study subjects. The study included a consecutive sample of patients on regular hemodialysis who presented to the hospital emergency department with established bleeding from the gastrointestinal tract

Correspondence to: A.A. Salman, Internal Medicine Department, Faculty of medicine, Cairo University, 100 L, Hadayek Al Ahram, 11311 Giza, Egypt. Phone : 00201000468664 , Fax : 002023747743.

E-mail : awea844@gmail.com

Submission date : 28/12/2019

Acceptance date : 18/05/2020 
or a recent attack (within one day) of hematemesis and/ or melena. Moreover, patients on regular hemodialysis who had ulcer hemorrhage that has begun after hospital admission for any other medical or surgical issues were enrolled in this study.

Inclusion criteria were patients on regular hemodialysis with an ulcer that showed either ongoing bleeding (jetting arterial or continuous trickling) or a nonbleeding lesion (nonbleeding detectable blood vessel or attached clot) at the time of endoscopic intervention. Hemodynamically unstable patients, at their initial presentation, were resuscitated at first and then considered for inclusion in the study if they became stable. Exclusion criteria were patients with malignant-looking ulcers or those with a flat spot or a clean base, patients with bleeding tendency (platelet count $<100,000$; international normalized ratio $>1.5$ ), or patients on antiplatelets or anticoagulants. Moreover, patients who were given PPI treatment prior to the index endoscopy were excluded from this study.

\section{Endoscopic Hemostasis}

The choice of the method of endoscopic bleeding control, whether the epinephrine bolus (1:10,000 dilution in saline, $1-1.5 \mathrm{~mL} /$ bolus) was used as monotherapy (unimodal) or in addition to either thermal (bipolar electrocoagulation or argon plasma coagulation) or mechanical (apposition of clips) therapy (multimodal), was done according to the estimate of the responsible endoscopist. Unimodal therapy with injection only was not the preferred choice (bimodal method was preferred).

Bleeding control was considered to be achieved if the bleeding had stopped. Endoscopic water pump was employed to wash clots that were covering ulcer lesions ; and then underlying nonbleeding detectable vessels or attached clots were managed endoscopically.

\section{Schedule of Intravenous PPIs}

Esomeprazole, omeprazole, or pantoprazole was used in the study. The selection was independent of researchers' predilection and was done according to the availability within the hospital. The study included 200 consecutive patients, the first one hundred patients were given an infusion of high-dose intensive approach (a loading dose of $80 \mathrm{mg}$ on day 1 , then constant infusion of $8 \mathrm{mg} / \mathrm{h}$ for $72 \mathrm{~h}$ ). The second one hundred patients were given the standard approach (40 mg bolus of PPI twice daily). Cases were then carried to a gastroenterology section for observation and pursuit of treatment.

Oral PPI therapy (20 mg twice daily) was started after the initial $72 \mathrm{~h}$, until patient discharge. Second endoscopy was individually employed in high-risk cases at admission, such as those presenting with shock but was obligatory in all cases with suspicion of rebleeding such as those with recurrence of hypotension or with hemoglobin drop. Approach of early start of feeding was adopted in the low-risk group.

Clinical suspicion of rebleeding was considered in patients who after an initial improvement developed one of the following: a decrease in systolic blood pressure $(\leq 100 \mathrm{mmHg})$, tachycardia $(\geq 100$ beats per min), fall in hemoglobin $(>20 \mathrm{~g} / \mathrm{L})$, no increase in hemoglobin levels with red blood cell transfusions, or re-occurrence of overt bleeding. Patients who had a clinical suspicion of rebleeding underwent a second attempt at endoscopic hemostasis : rebleeding was diagnosed if the ulcer was actively bleeding or if there was intragastric fresh blood.

The threshold for blood transfusion was $<7 \mathrm{gm} / \mathrm{dL}$ in most cases. Extreme caution was taken during transfusion of these patients on hemodialysis to avoid volume overload. The patient who needed blood transfusion was given the least possible number of packed red blood cells during the session of heparin-free hemodialysis.

The primary outcome measure was the occurrence of rebleeding during the hospital stay, diagnosed at a repeat endoscopy. Secondary outcome measures included the need for surgical intervention, transfusion requirement, length of hospital stay, and mortality.

\section{Statistical methods}

IBM@ SPSS $\odot$ Statistics version 23 (IBMC Corp., Armonk, NY, USA) was employed for statistical analysis. Numerical information was assigned as mean and standard deviation or median and range according to appropriateness. Frequency and percentage were used to express qualitative information. Chi-square test (Fisher's exact test) was employed to assess the relationship between qualitative variables. For quantitative information, the comparison between the two cohorts was performed employing independent sample t-test or Mann-Whitney test. A significant $\mathrm{p}$-value was $<0.05$.

\section{Results}

The two cohorts were compared in terms of the baseline features. There was a statistically significant difference between the two studied cohorts in age, and baseline

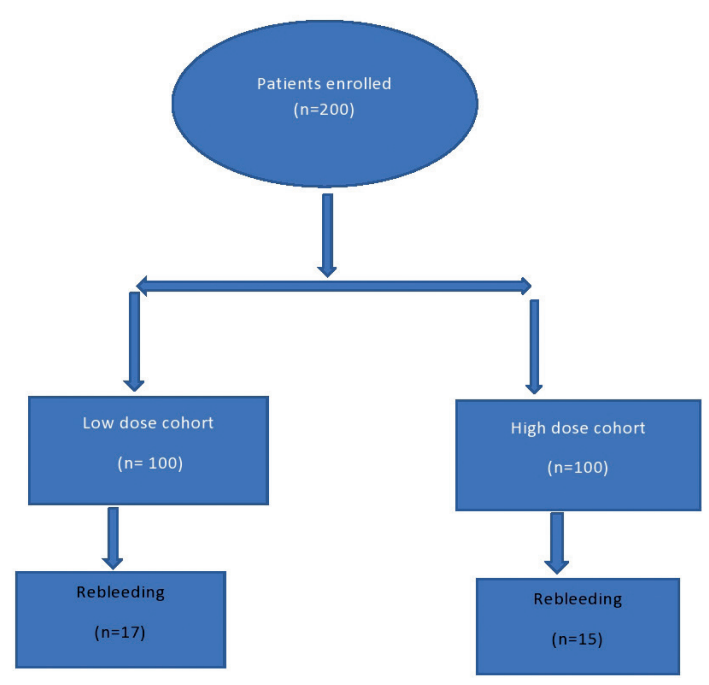

Figure 1. - Flow chart of patients included in the study. 
Table 1. - Characteristics of the two studied groups

\begin{tabular}{|c|c|c|c|}
\hline & $\begin{array}{c}\text { High Dose } \\
\mathbf{n}=100\end{array}$ & $\begin{array}{c}\text { Low Dose } \\
n=100\end{array}$ & p value \\
\hline Age (years) & $53.3 \pm 8.3$ & $55.7 \pm 7.7$ & 0.034 \\
\hline Sex (Male/ Female) & $60 / 40$ & $59 / 41$ & 0.885 \\
\hline Shock at presentation & $35(35.0 \%)$ & $39(39.0 \%)$ & 0.558 \\
\hline Use of NASID or aspirin & $50(50.0 \%)$ & $41(41.0 \%)$ & 0.201 \\
\hline \multicolumn{3}{|l|}{ Time from bleeding to endoscopy (hrs) } & \multirow{5}{*}{0.553} \\
\hline$<6$ & $29(29.0 \%)$ & $24(24.0 \%)$ & \\
\hline $6-12$ & $34(34.0 \%)$ & $29(29.0 \%)$ & \\
\hline $12-24$ & $22(22.0 \%)$ & $27(27.0 \%)$ & \\
\hline$>24$ & $15(15.0 \%)$ & $20(20.0 \%)$ & \\
\hline Previous ulcer disease & $23(23.0 \%)$ & $35(35.0 \%)$ & 0.061 \\
\hline Previous history of bleeding & $28(28.0 \%)$ & $22(22.0 \%)$ & 0.327 \\
\hline Serum creatinine $(\mathrm{mg} / \mathrm{dL})$ & $6.0 \pm 0.9$ & $5.7 \pm 1.2$ & 0.020 \\
\hline Hemoglobin level (d/dL) & $8.4 \pm 0.9$ & $8.0 \pm 0.8$ & $<0.001$ \\
\hline \multicolumn{4}{|l|}{ Site of the bleeding ulcer } \\
\hline Gastric & $37(37.0 \%)$ & $39(39.0 \%)$ & \multirow{2}{*}{0.771} \\
\hline Duodenal & $63(63.0 \%)$ & $61(61.0 \%)$ & \\
\hline \multicolumn{4}{|l|}{ Ulcer size $(\mathrm{mm})$} \\
\hline$<10$ & $45(45.0 \%)$ & $36(36.0 \%)$ & \multirow{3}{*}{0.404} \\
\hline $10-20$ & $37(37.0 \%)$ & $41(41.0 \%)$ & \\
\hline$>20$ & $18(18.0 \%)$ & $23(23.0 \%)$ & \\
\hline \multicolumn{4}{|l|}{ Forrest classification } \\
\hline Ia- Spurting & $15(15.0 \%)$ & $16(16.0 \%)$ & \multirow{4}{*}{0.745} \\
\hline Ib- Oozing & $28(28.0 \%)$ & $34(34.0 \%)$ & \\
\hline IIa- Non-bleeding visible vessel & $33(33.0 \%)$ & $27(27.0 \%)$ & \\
\hline IIb- Adherent clot & $24(24.0 \%)$ & $23(23.0 \%)$ & \\
\hline \multicolumn{4}{|l|}{ Endoscopic hemostasis modality } \\
\hline Unimodal & $40(40.0 \%)$ & $43(43.0 \%)$ & \multirow{2}{*}{0.667} \\
\hline Bimodal & $60(60.0 \%)$ & $57(57.0 \%)$ & \\
\hline \multicolumn{4}{|l|}{ Type of PPI used } \\
\hline Esomeprazole & $35(35.0 \%)$ & $37(37.0 \%)$ & \multirow{3}{*}{0.625} \\
\hline Omeprazole & $35(35.0 \%)$ & $39(39.0 \%)$ & \\
\hline Pantoprazole & $30(30.0 \%)$ & $24(24.0 \%)$ & \\
\hline Number of transfused packed RBCs & $1(0-4)$ & $1(0-4)$ & 0.972 \\
\hline No. of patients need $\geq 2$ units & $29(29 \%)$ & $28(28 \%)$ & 0.876 \\
\hline
\end{tabular}

Data are presented as mean $\pm \mathrm{SD}$, median (range) or number (\%).

serum creatinine and hemoglobin levels. However, the variability was within the clinically accepted ranges (Table 1).

Rebleeding occurred in 32 patients ; 15 in the HighDose Cohort and 17 in the Low-Dose Cohort with no considerable difference between the two groups $(\mathrm{p}=$ 0.700) (Figure 1). The characteristics of patients with rebleeding in the two cohorts are shown in Table 2. There were no considerable differences between the two dose groups regarding the time of rebleeding $(p=0.243)$, endoscopic hemostasis mode $(p=1.000)$, and need for surgery $(p=0.306)$. Seventeen patients died with an inhospital mortality rate of $8.5 \%$. The high-dose regimen In-hospital mortality in high-dose group was $9.0 \%$ compared to $8.0 \%$ in the low-dose group $(p=0.800)$.

Apart from the pre-hemostatic Forrest classification of ulcers, there were no significant differences between patients with re-bleeding ulcers $(n=32)$ and those with non-rebleeding $(n=168)$ in their clinical characteristics (Table 3). Rebleeding was more common in class Ia, i.e. spurting bleeders $(\mathrm{p}<0.001)$. Also, there was no considerable variation between the two cohorts in the period of hospitalization ; $8.1 \pm 1.6$ days in the rebleeding group vs. $8.3 \pm 1.7$ in those with no rebleeding $(\mathrm{p}=0.211)$. Ulcer rebleeding was not significantly associated with higher in-hospital mortality ; 4 patients $(12.5 \%)$ died in the rebleeding group compared to $13(7.7 \%)$ in the nonrebleeding group $(\mathrm{p}=0.376)$.

\section{Discussion}

The results of this work showed that high-dose PPIs do not offer more beneficial effect compared to low-dose PPIs in decreasing the rates of recurrent bleeding, surgical interference, or death post endoscopic hemostasis of bleeding peptic ulcers in cases on regular hemodialysis. Forrest classification of the bleeding ulcer was the only predictor of recurrent bleeding risk.

After initial resuscitation, endoscopic management remains the optimum treatment of high-risk ulcers. How- 
Table 2. - Characteristics of the 32 patients who developed rebleeding in the two studied groups

\begin{tabular}{|c|c|c|c|}
\hline & $\begin{array}{c}\text { High Dose } \\
n=15\end{array}$ & $\begin{array}{c}\text { Low Dose } \\
n=17\end{array}$ & $p$ value \\
\hline \multicolumn{4}{|l|}{ Time of rebleeding } \\
\hline Within 3 days & $9(60.0 \%)$ & $14(82.4 \%)$ & \multirow{2}{*}{0.243} \\
\hline After 3 days & $6(40.0 \%)$ & $3(17.6 \%)$ & \\
\hline \multicolumn{4}{|l|}{ Forrest classification } \\
\hline Ia- Spurting & $8(53.3 \%)$ & $7(41.2 \%)$ & \multirow{6}{*}{ * } \\
\hline Ib- Oozing & $2(13.3 \%)$ & $3(17.6 \%)$ & \\
\hline IIa- Non-bleeding visible vessel & $3(20.0 \%)$ & $4(23.5 \%)$ & \\
\hline IIb- Adherent clot & $0(0.0 \%)$ & $0(0.0 \%)$ & \\
\hline IIc- Ulcers with a flat spot & $1(6.7 \%)$ & $3(17.6 \%)$ & \\
\hline III- Clean base & $1(6.7 \%)$ & $0(0.0 \%)$ & \\
\hline Endoscopic Hemostasis & $13(86.7 \%)$ & $14(82.4 \%)$ & 1.000 \\
\hline Need for surgery & $5(33.3 \%)$ & $3(17.6 \%)$ & 0.306 \\
\hline
\end{tabular}

Data are presented as number $(\%)$ * no p-value due to the small number of cases in subgroups.

Table 3. - Comparison between patients who developed rebleeding and those who didn't

\begin{tabular}{|c|c|c|c|}
\hline & $\begin{array}{c}\text { Rebleeding } \\
\mathbf{n}=32\end{array}$ & $\begin{array}{c}\text { No Rebleeding } \\
n=168\end{array}$ & p value \\
\hline Age (years) & $54.8 \pm 9.4$ & $54.4 \pm 7.8$ & 0.837 \\
\hline Sex (Male/ Female) & $21 / 11$ & $98 / 70$ & 0.441 \\
\hline Shock at presentation & $15(20.3 \%)$ & $59(79.7 \%)$ & 0.207 \\
\hline Use of NASIDs or aspirin & $10(11.0 \%)$ & $81(89.0 \%)$ & 0.077 \\
\hline \multicolumn{4}{|l|}{ Time from bleeding to endoscopy (hrs) } \\
\hline$<6$ & $8(15.1 \%)$ & $45(84.9 \%)$ & \multirow{4}{*}{0.440} \\
\hline $6-12$ & $7(11.1 \%)$ & $56(88.9 \%)$ & \\
\hline $12-24$ & $11(22.4 \%)$ & $38(77.6 \%)$ & \\
\hline$>24$ & $6(17.1 \%)$ & $29(82.9 \%)$ & \\
\hline Previous ulcer disease & $7(12.1 \%)$ & $51(87.9 \%)$ & 0.332 \\
\hline Previous bleeding history & $7(14.0 \%)$ & $43(86.0 \%)$ & 0.656 \\
\hline \multicolumn{4}{|l|}{ Site of the bleeding ulcer } \\
\hline Gastric & $15(19.7 \%)$ & $61(80.3 \%)$ & \multirow{2}{*}{0.259} \\
\hline Duodenal & $17(13.7 \%)$ & $107(86.3 \%)$ & \\
\hline \multicolumn{4}{|l|}{ Ulcer size (mm) } \\
\hline$<10$ & $8(9.9 \%)$ & $73(90.1 \%)$ & \multirow{3}{*}{0.073} \\
\hline $10-20$ & $18(23.1 \%)$ & $60(76.9 \%)$ & \\
\hline$>20$ & $6(14.6 \%)$ & $35(85.4 \%)$ & \\
\hline \multicolumn{4}{|l|}{ Forrest classification } \\
\hline Ia- Spurting & $12(38.7 \%)$ & $19(61.3 \%)$ & \multirow{4}{*}{$<0.001$} \\
\hline Ib- Oozing & $10(16.1 \%)$ & $52(83.9 \%)$ & \\
\hline IIa- Non-bleeding visible vessel & $9(15.0 \%)$ & $51(85.0 \%)$ & \\
\hline IIb- Adherent clot & $1(2.1 \%)$ & $46(97.9 \%)$ & \\
\hline \multicolumn{4}{|l|}{ Endoscopic hemostasis modality } \\
\hline Unimodal & $9(10.8 \%)$ & $74(89.2 \%)$ & \multirow{2}{*}{0.094} \\
\hline Bimodal & $23(19.7 \%)$ & $94(80.3 \%)$ & \\
\hline \multicolumn{4}{|l|}{ Type of PPI used } \\
\hline Esomeprazole & $9(12.5 \%)$ & $63(87.5 \%)$ & \multirow{3}{*}{0.251} \\
\hline Omeprazole & $16(21.6 \%)$ & $58(78.4 \%)$ & \\
\hline Pantoprazole & $7(13.0 \%)$ & $47(87.0 \%)$ & \\
\hline \multicolumn{4}{|l|}{ PPI Dose } \\
\hline High Dose & $15(15.0 \%)$ & $85(85.0 \%)$ & \multirow{2}{*}{0.700} \\
\hline Low Dose & $17(17.0 \%)$ & $83(83.0 \%)$ & \\
\hline
\end{tabular}

Data are presented as mean \pm SD or number (\%).

ever, despite the advances in endoscopic techniques, rebleeding is still a threat to nearly $10 \%$ to $20 \%$ of patients with a mortality rate of $4 \%$ (19). Therefore, prevention of ulcer rebleeding is crucial to accomplish the mission of optimal management of emergency ulcer hemorrhage. Gastric acidity was shown to antagonize hemostasis inside the stomach and duodenum. It precludes clot synthesis and enhances lysis of existing clots. In vitro studies showed that platelet aggregation is compromised at gastric juice of $\mathrm{pH}$ 6.4. (20). In the current practice, acid suppression medication in combination with endoscopic therapy is the backbone of treatment of peptic ulcer 
bleeding $(21,22)$. A systematic review of 24 randomized controlled trials (RCTs) has demonstrated much superior efficacy of PPIs compared to $\mathrm{H}_{2}$-receptor antagonists in this regard (19).

Yet, the best approach for post-endoscopy PPI dosing remains undefined. Consensus statements have recommended a high-dose PPI regimen $(80 \mathrm{mg}$ followed by an infusion of $8 \mathrm{mg} / \mathrm{h}$ for $72 \mathrm{~h}$ ) to decrease recurrent bleeding and death in cases with high-risk stigmata $(15,23,24)$. Other studies found low-dose regimens to be effective in reducing gastric acidity as well $(25,26)$.

Many investigators initiated RCTs to compare the high dose-intensive approach with the standard regimen of $40 \mathrm{mg}$ bolus daily ensued by saline infusion for $72 \mathrm{~h}$. Andriulli et al. (27) did not find the high-dose regimen to be more effective in decreasing the rate of rebleeding after endoscopic hemostasis. Similar findings were reported by other investigators (28-31)

The main target of PPI administration is to keep gastric $\mathrm{pH}>6$ to promote clot stabilization in an ideal condition for cure of peptic ulcer (32). High-dose IV continuous PPI infusion is supposed to provide the most potent acid suppression. An intravenous bolus inhibits stimulated parietal cells with active proton pumps; then continuous infusion can inactivate any newly synthesized proton pumps (33). Clinical studies did not support this theoretical advantage of the high-dose regimen. Javid et al. (34) compared the effect of IV infusion versus oral PPIs on intragastric $\mathrm{pH}$ following endoscopic therapy for a bleeding peptic ulcer. All patients attained a mean 72 $\mathrm{h}$ intragastric $\mathrm{pH}$ of $>6$ with no considerable variations between the oral and parenteral approaches.

The current study and many others (27-28,35) challenge the guidelines recommending an IV followed by continuous infusion PPI therapy $(15,16,36,37)$. However, more recent guidelines suggest considering intermittent high doses of oral or intravenous PPI rather than continuous infusion $(36,37)$. The current study supports intermittent standard doses of IV PPI.

On the other hand, the prevalence of cases with advanced chronic renal failure who requires hemodialysis constitutes a major load on the health budget. (38) Bleeding from the gastrointestinal tract is not uncommon is cases with end-stage renal disease. (39)

Past reports have demonstrated an increased risk of upper GI bleeding in these patients compared to the general population in addition to elevated death rates. (40)

To our knowledge, this is the first prospective work that compares high- versus low-dose PPI postendoscopic hemostasis in this special group of patients on hemodialysis. Multiple factors make these patients a high-risk group of upper GI bleeding. These factors include uremia-related platelet dysfunction, old age, associated arteriovenous malformations, anemia, and numerous co-morbidities $(11,12,41)$. These patients are commonly exposed to drugs that impacts the coagulation cascade such as non-steroidal anti-inflammatory drugs
(NSAIDs), antiplatelets, and anticoagulants (12,13). These factors contributes to higher risk of rebleeding, transfusions, longer hospital stay, surgical intervention, and mortality $(42,43)$. The risk of rebleeding is enhanced up to one year after primary treatment (44).

In spite of this, the current work has some limitations. The principal limitation of this study was reporting only in-hospital outcome without post-discharge follow up. According to previous studies, rebleeding after discharge may occur, but bleeding mostly recurred within the first $72 \mathrm{~h}(28,45,46)$. It is probable we did not miss a high number of cases in view of the mean duration of hospital stay in the current study.

Another limitation is the non-randomized nature of the study that may affect the generalizability of the results. Further randomized studies are warranted for objective validation of the study outcomes.

Furthermore, it should be also noted that the recommendations of guidelines are against unimodal treatment because of high rebleeding risk. However, in this study, $40 \%$ of the patients had this type of hemostasis. This is largely related to limited resources which many centers are facing and this could have some potential influence on the results.

In summary, we can conclude the endoscopic hemostasis followed by the standard low-dose PPI strategy of $40 \mathrm{mg}$ daily IV boluses are safe and effective treatment of bleeding peptic ulcers in the high-risk patients under regular hemodialysis. The high-dose continuous infusion regimen did not improve the treatment outcome in terms of rebleeding rate, need for surgery, hospital stay, and inhospital mortality.

\section{No conflicts of interest or funding resources.}

\section{References}

1. JAIRATH V, DESBOROUGH MJR. Modern-day management of upper gastrointestinal haemorrhage. Transfus Med. Oxf. Engl., 2015, 25 : 351-357.

2. MARINKO MARUŠIĆ, ANTONIO KLEMENČIĆ, ROSANA TROSKOT PERIĆ, GORAN HAUSER. Gastroesophageal Variceal Bleeding - An Overview of Current Treatment Options. Acta Gastroenterol. Belg., 2018, 81 : 305-317.

3. JAIRATH V, BARKUN AN. Improving outcomes from acute upper gastrointestinal bleeding. Gut, 2012, 61 : 1246-1249.

4. BOONPONGMANEE S, FLEISCHER DE, PEZZULLO JC, COLLIER K, MAYORAL W, AL-KAWAS F, et al. The frequency of peptic ulcer as a cause of upper-GI bleeding is exaggerated. Gastrointest. Endosc., 2004, 59 : 788794.

5. LOPERFIDO S, BALDO V, PIOVESANA E, BELLINA L, ROSSI K, GROPPO M, et al. Changing trends in acute upper-GI bleeding: a populationbased study. Gastrointest. Endosc., 2009, 70 : 212-224.

6. KUO CC, KUO HW, LEE IM, LEE CT, YANG CY. The risk of upper gastrointestinal bleeding in patients treated with hemodialysis: a populationbased cohort study. BMC Nephrol., 2013, $14: 15$.

7. WASSE H, GILLEN DL, BALL AM, KESTENBAUM BR, SELIGER SL, SHERRARD D, et al. Risk factors for upper gastrointestinal bleeding among end-stage renal disease patients. Kidney Int., 2003, 64 : 1455-1461.

8. SOOD P, KUMAR G, NANCHAL R, SAKHUJA A, AHMAD S, ALI M, et al. Chronic kidney disease and end-stage renal disease predict higher risk of mortality in patients with primary upper gastrointestinal bleeding. Am. J. Nephrol., 2012, $35:$ 216-224.

9. IKEDA N, INOUE T, KOBAYASHI K, WATANABE Y, SUZUKI H. Emergency Gastrointestinal Bleeding in Dialysis Patients: Five Years' Experience in a Single Dialysis Center. Urol. Nephrol. Open Access J., 2015, 2 : 00021. 
10. NEGRI AL, KIDO N, ESTRAVIZ HO, MORELLI OH, MORELLI OH. Upper gastrointestinal bleeding in patients in chronic hemodialysis. Nephron., 1994, $67: 130$

11. LIANG CC, WANG SM, KUO HL, CHANG CT, LIU JH, LIN HH, et al. Upper Gastrointestinal Bleeding in Patients with CKD. Clin. J. Am. Soc. Nephrol. CJASN., 2014, 9 : 1354-1359.

12. KALMAN RS, PEDROSA MC. Evidence-based review of gastrointestinal bleeding in the chronic kidney disease patient. Semin. Dial., 2015, 28 : 68-74.

13. YANG JY, LEE TC, MONTEZ-RATH ME, PAIK J, CHERTOW GM, DESAI $\mathrm{M}$, et al. Trends in Acute Nonvariceal Upper Gastrointestinal Bleeding in Dialysis Patients. J. Am. Soc. Nephrol. JASN., 2012, 23 : 495-506.

14. KLEIN A, GRALNEK IM. Acute, nonvariceal upper gastrointestinal bleeding. Curr. Opin. Crit. Care, 2015, 21 : 154-62.

15. BARKUN AN, BARDOU M, KUIPERS EJ, SUNG J, HUNT RH, MARTEL $\mathrm{M}$, et al. International consensus recommendations on the management of patients with nonvariceal upper gastrointestinal bleeding. Ann. Intern. Med., 2010, $152: 101-13$.

16. LAINE L, JENSEN DM. Management of patients with ulcer bleeding. Am. J. Gastroenterol., 2012, 107 : 345-360.

17. HOLSTER IL, KUIPERS EJ. Management of acute nonvariceal upper gastrointestinal bleeding: Current policies and future perspectives. World $J$. Gastroenterol. WJG., 2012, 18 : 1202-1207.

18. LAEEQ SM, TASNEEM AA, HANIF FM, LUCK NH, MANDHWANI R, WADHVA R. Upper Gastrointestinal Bleeding in Patients with End Stage Renal Disease: Causes, Characteristics and Factors Associated with Need for Endoscopic Therapeutic Intervention. J. Transl. Intern. Med., 2017, 5 : 106111.

19. LEONTIADIS GI, SHARMA VK, HOWDEN CW. Proton pump inhibitor treatment for acute peptic ulcer bleeding. Cochrane Database Syst. Rev., 2004, 3 : CD002094.

20. GREEN FW, KAPLAN MM, CURTIS LE, LEVINE PH. Effect of acid and pepsin on blood coagulation and platelet aggregation. A possible contributor prolonged gastroduodenal mucosal hemorrhage. Gastroenterology., 1978, 74 : $38-43$.

21. JAVID G, MASOODI I, ZARGAR SA, KHAN BA, YATOO GN, SHAH AH, et al. Omeprazole as adjuvant therapy to endoscopic combination injection sclerotherapy for treating bleeding peptic ulcer. Am. J. Med., 2001, $111: 280$ 284.

22. VAN RENSBURG CJ, CHEER S. Pantoprazole for the Treatment of Peptic Ulcer Bleeding and Prevention of Rebleeding. Clin. Med. Insights Gastroenterol., 2012, 5 : 51-60.

23. PALMER K. Non-variceal upper gastrointestinal haemorrhage : guidelines. Gut, 2002, $51: 1-6$.

24. GREENSPOON J, BARKUN A. A summary of recent recommendations on the management of patients with nonvariceal upper gastrointestinal bleeding. Pol. Arch. Med. Wewn., 2010, $120: 341-346$.

25. CHOI KD, KIM N, JANG I-J, PARK YS, CHO JY, KIM J-R, et al. Optimal dose of intravenous pantoprazole in patients with peptic ulcer bleeding requiring endoscopic hemostasis in Korea. J. Gastroenterol. Hepatol., 2009, 24 : 1617-1624.

26. OH JH, CHOI MG, DONG MS, PARK JM, PAIK CN, CHO YK, ET AL. Low-dose intravenous pantoprazole for optimal inhibition of gastric acid in Korean patients. J. Gastroenterol. Hepatol., 2007, 22 : 1429-1434.

27. ANDRIULLI A, LOPERFIDO S, FOCARETA R, LEO P, FORNARI F, GARRIPOLI A, et al. High- versus low-dose proton pump inhibitors after endoscopic hemostasis in patients with peptic ulcer bleeding: a multicentre, randomized study. Am. J. Gastroenterol., 2008, 103 : 3011-3018.

28. UDD M, MIETTINEN P, PALMU A, HEIKKINEN M, JANATUINEN E, PASANEN $\mathrm{P}$, et al. Regular-dose versus high-dose omeprazole in peptic ulcer bleeding: a prospective randomized double-blind study. Scand. J. Gastroenterol., 2001, 36 : 1332-1338.
29. CHEN CC, LEE JY, FANG YJ, HSU SJ, HAN ML, TSENG PH, et al. Randomised clinical trial: high-dose vs. standard-dose proton pump inhibitors for the prevention of recurrent haemorrhage after combined endoscopic haemostasis of bleeding peptic ulcers. Aliment. Pharmacol. Ther., 2012, 35 : 894-903.

30. HSU YC, PERNG CL, YANG TH, WANG CS, HSU WL, WU HT, et al. A randomized controlled trial comparing two different dosages of infusional pantoprazole in peptic ulcer bleeding. Br. J. Clin. Pharmacol., 2010, 69 : 245 51.

31. MASJEDIZADEH AR, HAJIANI E, ALAVINEJAD P, HASHEMI SJ, SHAYESTEH AA, JAMSHIDIAN N. High Dose versus Low Dose Intravenous Pantoprazole in Bleeding Peptic Ulcer : A Randomized Clinical Trial. Middle East J. Dig. Dis., 2014, 6 : 137-143.

32. BARKUN AN, COCKERAM AW, PLOURDE V, FEDORAK RN. Review article: acid suppression in non-variceal acute upper gastrointestinal bleeding. Aliment. Pharmacol. Ther., 1999, 13 : 1565-1584.

33. WELAGE LS. Pharmacologic features of proton pump inhibitors and their potential relevance to clinical practice. Gastroenterol. Clin. North Am., 2003, $32: 25-35$.

34. JAVID G, ZARGAR SA, SAIF UR, KHAN BA, YATOO GN, SHAH AH, et al. Comparison of p.o. or i.v. proton pump inhibitors on 72-h intragastric $\mathrm{pH}$ in bleeding peptic ulcer. J. Gastroenterol. Hepatol., 2009, 24 : 1236-1243.

35. BAJAJ JS, DUA KS, HANSON K, PRESBERG K. Prospective, randomized trial comparing effect of oral versus intravenous pantoprazole on rebleeding after nonvariceal upper gastrointestinal bleeding : a pilot study. Dig. Dis. Sci., 2007, $52: 2190-2194$.

36. SUNG JJ, CHIU PW, CHAN FKL, LAU JY, GOH KL, HO LH, et al. AsiaPacific working group consensus on non-variceal upper gastrointestinal bleeding: an update 2018. Gut, 2018, $67: 1757-1768$

37. GRALNEK IM, DUMONCEAU J-M, KUIPERS EJ, LANAS A, SANDERS DS, KURIEN M, et al. Diagnosis and management of nonvariceal upper gastrointestinal hemorrhage : European Society of Gastrointestinal Endoscopy (ESGE) Guideline. Endoscopy, 2015, 47 : 1-46.

38. KUO CC, KUO HW, LEE IM, LEE CT, YANG CY. The risk of upper gastrointestinal bleeding in patients treated with hemodialysis: a populationbased cohort study. BMC Nephrol., 2013, $14: 15$

39. PINELLI G, TOMASELlO G, DAMIANI F, DAMIANI P, MONTE AI Endoscopic findings in chronic renal failure: review of literature. Acta Medica Mediterranea, 2012, $28:$ 261-265.

40. LAEEQ SM, TASNEEM AA, HANIF FM, LUCK NH, MANDHWANI R, WADHVA R. Upper Gastrointestinal Bleeding in Patients with End Stage Renal Disease : Causes, Characteristics and Factors Associated with Need for Endoscopic Therapeutic Intervention. J. Transl. Int. Med., 2017, 5 : 106-111.

41. CHALASANI N, COTSONIS G, WILCOX CM. Upper gastrointestinal bleeding in patients with chronic renal failure : role of vascular ectasia. Am. $J$. Gastroenterol., 1996, 91 : 2329-2332.

42. PARASA S, NAVANEETHAN U, SRIDHAR ARM, VENKATESH PGK, OLDEN K. End-stage renal disease is associated with worse outcomes in hospitalized patients with peptic ulcer bleeding. Gastrointest. Endosc., 2013, $77: 609-616$.

43. CHeUnG J, YU A, LABOssiere J, ZHU Q, FEDORAK RN. Peptic ulcer bleeding outcomes adversely affected by end-stage renal disease. Gastrointest. Endosc., 2010, $71: 44-49$.

44. WU CY, WU MS, KUO KN, WANG CB, CHEN YJ, LIN JT. Long-term peptic ulcer rebleeding risk estimation in patients undergoing haemodialysis: a 10-year nationwide cohort study. Gut, 2011, 60 : 1038-1042.

45. JENSEN DM, EKLUND S, PERSSON T, AHLBOM H, STUART R, BARKUN AN, et al. Reassessment of Rebleeding Risk of Forrest IB (Oozing) Peptic Ulcer Bleeding in a Large International Randomized Trial. Am. J. Gastroenterol., 2017, 112 : 441-446.

46. OUALI SE, BARKUN AN, MARTEL M, MAGGIO D. Timing of rebleeding in high-risk peptic ulcer bleeding after successful hemostasis: A systematic review. Can. J. Gastroenterol. Hepatol., 2014, 28 : 543-548. 